\title{
Mechanical Shaking and Baling of Balsam Fir Trees Influence Postharvest Needle Senescence and Abscission
}

\author{
Ernest A. Korankye, Rajasekaran R. Lada*, Samuel K. Asiedu, Claude Caldwell \\ Department of Plant, Food, and Environmental Sciences, Faculty of Agriculture, Dalhousie University, Halifax, NS, Canada \\ Email: *raj.lada@dal.ca
}

How to cite this paper: Korankye, E.A., Lada, R.R., Asiedu, S.K. and Caldwell, C. (2018) Mechanical Shaking and Baling of Balsam Fir Trees Influence Postharvest Needle Senescence and Abscission. American Journal of Plant Sciences, 9, 339-352. https://doi.org/10.4236/ajps.2018.93027

Received: December 6, 2017

Accepted: February 9, 2018

Published: February 12, 2018

Copyright $\odot 2018$ by authors and Scientific Research Publishing Inc. This work is licensed under the Creative Commons Attribution International License (CC BY 4.0).

http://creativecommons.org/licenses/by/4.0/

\begin{abstract}
This study investigated the influence of both shaking duration and number of trees per bale on postharvest needle characteristics such as percentage needle loss, needle retention duration and explored the physiological roles of endogenous ethylene and volatile terpene compounds (VTCs). To accomplish these objectives, 25 six-year-old trees were detached and exposed to a range of shaking durations ( 0 to $60 \mathrm{sec}$.), and 30 six-year-old detached trees were exposed to baling treatments from 0 to 5 trees. Response variables measured were percent needle loss, needle retention duration, average water use, ethylene and volatile terpene compound evolution. Trees shaken for 60 seconds lost $16 \%$ less needle compared to control, which was consistent with the decrease in percent needle loss with increasing shaking duration. Baled trees lost $13 \%$ more needles compared to control, but percent needle loss was observed to decrease with increasing number of trees in a bale. These trends corresponded with increasing ethylene and VTC evolutions, where the longer the shaking duration or larger number of trees in a bale, the higher the ethylene and VTC evolutions. One can therefore draw inference that mechanical perturbation as a result of shaking and baling induce biosynthesis and regulation of ethylene and VTC in balsam fir trees in an effort to regulate postharvest needle abscission.
\end{abstract}

\section{Keywords}

Shaking, Baling, Ethylene, Volatile Terpene Compounds, Needle Loss, Thigmomorphogenesis

\section{Introduction}

Common practices among Christmas tree growers and exporters are shaking 
and baling of the trees. Shaking of trees is done in an attempt to meet international-market quarantine standards since the practice is known to reduce or remove dust, pollen, debris and molds off the trees, and remove any dead needles, broken branches and hidden insects [1]. Baling of trees help shrink the sizes of trees, for easy handling and create more room for storage and transportation leading to eventual cut in storage and transportation costs. However, postharvest shaking and baling of trees have been suggested to cause mechanical stress, contributing to a significant negative effect on postharvest qualities of trees [2]. Mechanical stresses caused through shaking and baling of trees can cause physiological perturbations, which may cause postharvest needle abscission. Such a mechanically-induced postharvest stress has been reported in several species [3] [4] [5]. Mechanical perturbations as a result of wind, rain, handling and predations are among the many environmental stimuli to which plants respond [4] [6].

Plants have the ability to sense a range of forces from very intense and physical damage to more moderate ones, and respond to these mechanical stimuli immediately or over time, depending on the level of stress perceived [7] [8] [9] by a phenomenon called "Thigmomorphogenesis" [4] [6]. Plants mostly do so by synthesizing an array of phytohormones and other VTCs in addition to expressing defense-related genes [4] [10] mostly resulting in growth retardation, leaf senescence and possibly organ abscission [11]. It has been reported that shaking of cocklebur plants causes an increase in the rate of leaf senescence [12]. Similar studies have shown that plants respond to mechanical stimuli by alteration in chlorophyll content and stomata closure leading to senescence and abscission [3]. It has also been established that mechanical damage of balsam fir trees through harvesting results in increase in ethylene evolution, a major contributing factor to postharvest needle abscission in balsam fir trees [13].

A similar phenomenon of mechanical perturbation is speculated to occur in root-detached balsam fir trees, from harvesting, shaking to baling of the trees. The trees go through mechanical perturbation and then initiate immediate survival responses such as stomatal closure with the consequence of lower photosynthetic rate, initiating the synthesis of phytohormones such as ethylene [13] in the long term, and volatile terpene compounds (VTCs) [14] all leading to the process of senescence and abscission in an attempt to communicate distress to immediate surrounding ecosystem in attempt to survive [5] [15]. It is hypothesized that shaking and baling of root-detached trees negatively impact needle retention of balsam fir Christmas trees. The objective of this study was to establish physiological effect of mechanical shaking and baling on postharvest needle abscission of balsam fir trees.

\section{Materials and Methods}

Full root-detached 6-year-old trees of $91 \mathrm{~cm}$ average height were used in this study. All the trees were harvested during the regular harvesting season of 
Christmas trees in November. Prior to harvesting, visual inspection was conducted to avoid pest or disease infestation on the trees. Harvesting of trees was done using a handheld chainsaw as per the normal practice. In this study, there were two separate experiments. The first experiment which focused on the effect of shaking durations on postharvest needle retention followed a completely randomized design. Tree shaking durations ranged from 0 (control), 10, 15, 30 and 60 seconds. Each of the 5 experimental units had five trees, hence a total of 25 trees were selected for the experiment. After treatment, trees were weighed and set up in $4 \mathrm{~L}$ glass jars containing $3 \mathrm{~L}$ of water. The glass jars were refilled whenever water levels dropped significantly and the amount of water added recorded, and factored into the estimation of water uptake by trees.

The second experiment focused on the effect of baling on postharvest needle retention and followed a randomized experimental design with the number of trees in a bale as the only factor. Six levels of tree baling were selected and these were 0 (no baling-control), 1, 2, 3, 4 and 5 trees per bale and replicated 5 times, bringing the total to 30 trees selected. Trees were weighed and set up in $4 \mathrm{~L}$ glass jars containing $3 \mathrm{~L}$ of water. Glass jars were refilled whenever water levels dropped significantly and the amount of water added recorded, and factored into the estimation of water uptake by trees.

Response variables measured were (i) percent needle loss-PNL (\%), (ii) needle retention duration-NRD (day), (iii) average water use (AWU) per gram of fresh weight $\left(\mathrm{mL} \cdot \mathrm{g}^{-1} \cdot \mathrm{d}^{-1}\right)$, (iv) ethylene evolution $\left(\mu \mathrm{L} \cdot \mathrm{g}^{-1} \cdot \mathrm{h}^{-1}\right)$ and $(\mathrm{v})$ VTC evolution $\left(\mathrm{mM} \cdot \mathrm{g}^{-1} \cdot \mathrm{h}^{-1}\right)$. These variables were measured following modified procedures tested to be effective in achieving the target results as detailed below;

\subsection{Percentage Needle Loss (PNL)}

To account for the needle loss on each tree, newly dropped needles were weighed. Since balsam fir needles have the ability to stay connected to the branches even after abscission, a process known as 'finger runs test' has been adopted. This is achieved by rubbing fingers through the tree to cause abscised needles to drop. Dropped needles are weighed and placed in oven for $48 \mathrm{hrs}$ at $80^{\circ} \mathrm{C}$ [13]. Needle loss was monitored throughout the experimental duration to estimate the percentage needle loss for each treatment.

\subsection{Needle Retention Duration (NRD)}

The primary assessment of needle abscission used in this study was by NRD, which is defined as the number of days for a complete needle abscission per tress [13].

\subsection{Average Water Use (AWU)}

Average water use $\left(\mathrm{mL} \cdot \mathrm{g}^{-1} \cdot \mathrm{d}^{-1}\right)$ is also monitored as the sum of the change in mass of the apparatus (excluding mass loss due to abscission) per unit fresh weight of needles over the duration of the experiment or until a branch had lost 
all needles [13]. AWU was estimated daily and calculated by the following equation:

$$
\text { AWU }=\frac{(\text { Initial Mass }- \text { Final Mass })-\text { Needle Mass }}{\text { Time }(\text { Days to complete needle loss })}
$$

\subsection{Ethylene Evolution ( $\left.\mu \mathrm{L}^{\cdot} \mathrm{g}^{-1} \cdot \mathrm{h}^{-1}\right)$}

Ethylene evolution was determined by first incubating trees in airtight plastic bag chambers for 12 hours. $1 \mu \mathrm{l}$ air samples were collected from the chamber and analyzed using gas chromatography (GC) equipped with flame ionization detector (FID). Evolution rates from the trees were calculated by the following equation:

Ethylene evolution

$$
=\frac{\text { Ethylene concentration }(\text { Initial }- \text { Final }) \times \text { Volume of incubation chamber }(L)}{12 \mathrm{~h} \times \operatorname{Mass}(\text { weight of tree })}
$$

where ethylene evolution is in $\mu \mathrm{L} \cdot \mathrm{g}^{-1} \cdot \mathrm{h}^{-1}$, concentration is in $\mu \mathrm{L} \cdot \mathrm{L}^{-1}$, and mass is the fresh weight $(\mathrm{g})$ of a tree. Volume of airtight incubation plastic bag (109.21 L).

\subsection{VTC Evolution ( $\left.\mathrm{mM}^{\mathrm{M}} \cdot \mathrm{g}^{-1} \cdot \mathrm{h}^{-1}\right)$}

To analyze VTC, whole trees were sealed in airtight plastic bag chambers for 30 mins. Within that period, solid phase micro-extraction (SPME) fiber was exposed to the headspace for VTC extraction. GC analysis was performed and the chromatographic data of peak area (PA) against retention time (minutes) for each of the samples were defined. Confirmation of terpene compounds were established by comparison of retention times and peak areas with that of known standard. The respective relative abundances for each sample were normalized against $\beta$-pinene standard (Sigma-Aldrich Co. LLC, Canada). Concentration of individual and total VTCs in $\mathrm{mM}$ per fresh weight of trees in $\mathrm{g}$ was estimated and the evolution was calculated per the incubation period of 30 mins.

For all analyses, statistical assumptions such as, constant variance, independence and normality were tested prior to ANOVA using Minitab 17 (Minitab 17, Minitab Inc., PA, USA). The main effects tested were shaking and baling. PNL. $\mathrm{NRD}$, AWU, ethylene and VTC evolutions met normality assumptions and hence ANOVA was performed on these parameters. A Tukey's least significant difference (LSD) test was used to establish the treatment differences upon significant effects.

\section{Results}

1) Percent needle loss (PNL)-ANOVA test performed showed that duration of tree shaking and number of trees in a bale had a significant effect on PNL (Table 1). A significant needle loss was observed when trees were shaken compared to the control, resulting in the control losing approximately $16 \%$ more 
needles than trees shaken for 60 seconds at the end of the experiment. Trees shaken for 10, 15 or 30 seconds loss $66.2 \%, 62.0 \%$ and $57.2 \%$ needles, respectively (Figure 1). Baling of trees was influenced PNL (Table 1). A significant decline in PNL with increase in number of trees per bale, and the control loss $13 \%$ less needles compared to the bale of 1 tree which loss the highest percent of needles (Figure 2). PNL was 2.5-fold higher in shaken trees compared to baled trees (Figure 5(a)). Cumulative PNL trends in both shaken and baled trees showed that peak needle loss commenced 3 weeks postharvest. Within that period a significant increase, up to $35 \%$ in needle loss of shaken trees was recorded. Contrary, baled tress loss $10 \%$ needles. It was also observed that shaken trees

Table 1. Statistical $\mathrm{p}$ values for the main effects of shaking duration, hydration condition and number trees per bale on postharvest characteristics of balsam fir based on ANOVA.

\begin{tabular}{ccccc}
\hline Source of variation & PNL & NRD & AWU Ethylene Evo. & VTC Evo. \\
\hline Shaking duration & $<\mathbf{0 . 0 0 1 ^ { * }}$ & $<\mathbf{0 . 0 0 1 ^ { * }}$ & 0.587 & $\mathbf{0 . 0 4 1}^{*}-$ \\
Number of trees per bale & $<\mathbf{0 . 0 0 1 ^ { * }}$ & $\mathbf{0 . 0 0 2}^{*}$ & 0.444 & $\mathbf{0 . 0 4 8}^{*} \mathbf{0 . 0 3 4 ^ { * }}$
\end{tabular}

${ }^{*}$ denotes a significant effect where $\mathrm{p} \leq 0.05$.

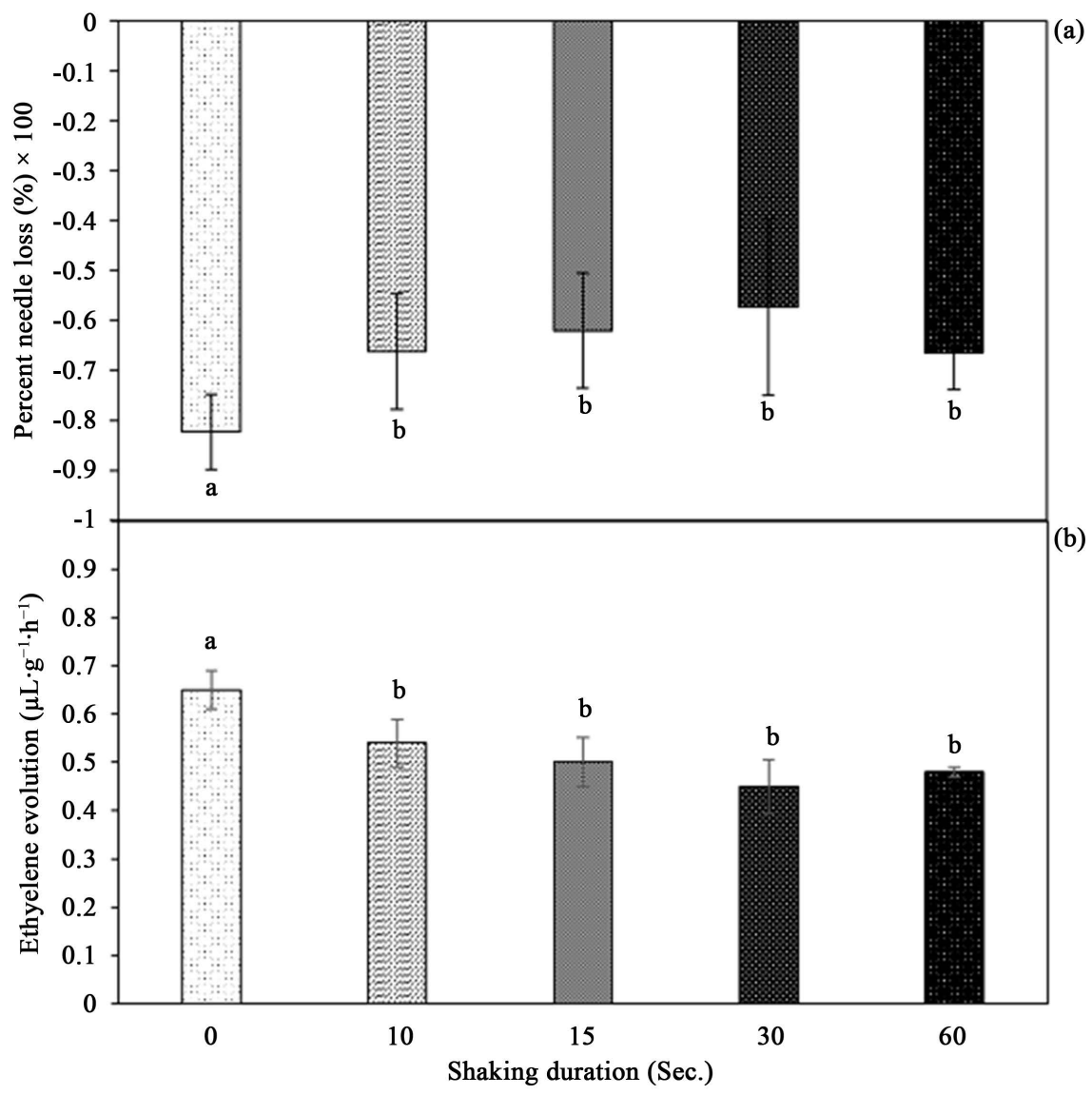

Figure 1. (a) Percent needle loss (\%) and (b) Ethylene evolution $\left(\mu \mathrm{L} \cdot \mathrm{g}^{-1} \cdot \mathrm{h}^{-1}\right)$ of shaken balsam fir trees for a duration with standard error bars $(n=5)$. Any two means followed by same letters are not significantly different $(\mathrm{p} \leq 0.05)$. 


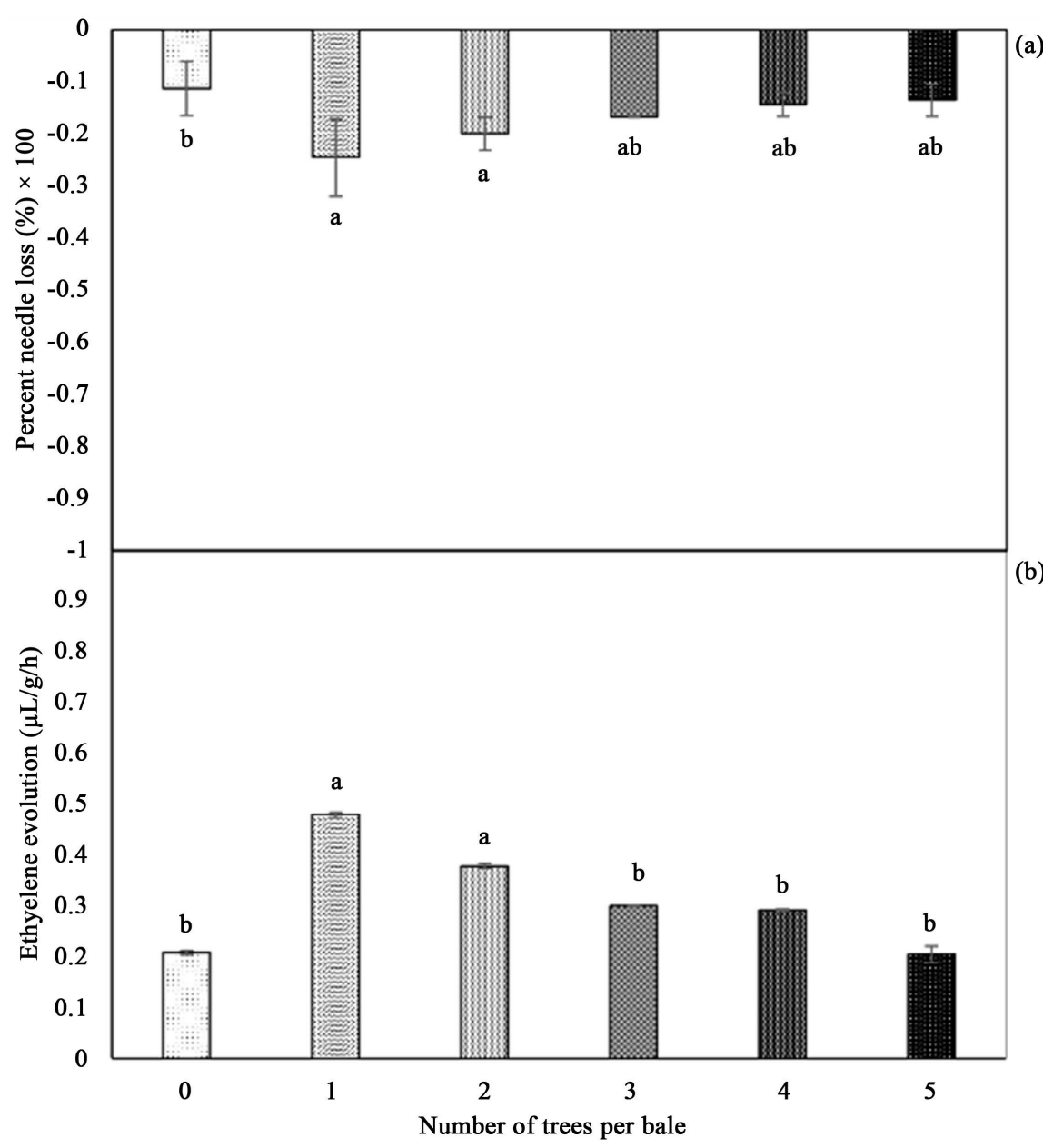

Figure 2. (a) Percent needle loss (\%) and (b) Ethylene evolution $\left(\mu \mathrm{L} \cdot \mathrm{g}^{-1} \cdot \mathrm{h}^{-1}\right)$ of baled balsam fir trees with their standard error bars $(n=5)$. Any two means followed by same letters are not significantly different $(\mathrm{p} \leq 0.05)$.

lasted for 7 weeks after harvest losing $80 \%$ of needles, while baled trees lasted 9 weeks, losing a total of $57 \%$ needles (Figure 3 ).

2) Needle retention duration (NRD) - NRD was estimated as number of days to $10 \%$ needle loss since most trees lose their market value by $10 \%$ needle loss. The data showed that duration of tree shaking and hydration condition had a statistically significant effect on NRD ( $p<0.001)$ (Table 1$)$. A pattern of increased days to $10 \%$ needle loss by shaking up to 15 seconds was seen. After 15 seconds of shaking there was a decline in needle loss as days progressed. The best performed trees were those shaken for 15 seconds, which took almost two-fold increase in days to lose $10 \%$ of its needle, compared to the unshaken control (Figure 4). Baling of trees had a significant effect on NRD $(p=0.002)$ (Table 1). A linear trend of increased days to $10 \%$ needle loss with increasing number of trees per bale until 3 trees in a bale was seen. After that, a decline in days to $10 \%$ needle loss in 4 and 5 trees per bale was observed. Among the 5 levels of treatments, approximately two-fold increase in days to $10 \%$ needle loss in the bale of 3 trees compared to the control was observed (Figure 5). 


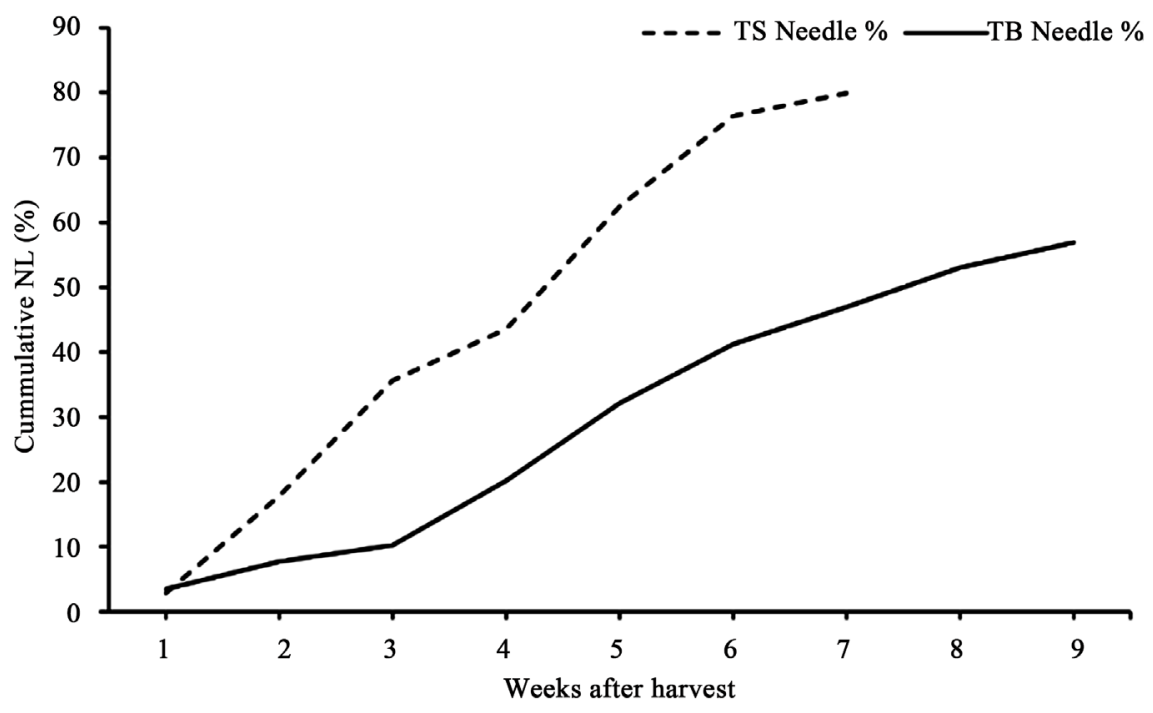

Figure 3. Cumulative PNL of shaken tree (TS) and baled tree (TB). The continuous line indicate trend observed with PNL of the baled treatment. The broken lines indicate the PNL of shaking treatment.

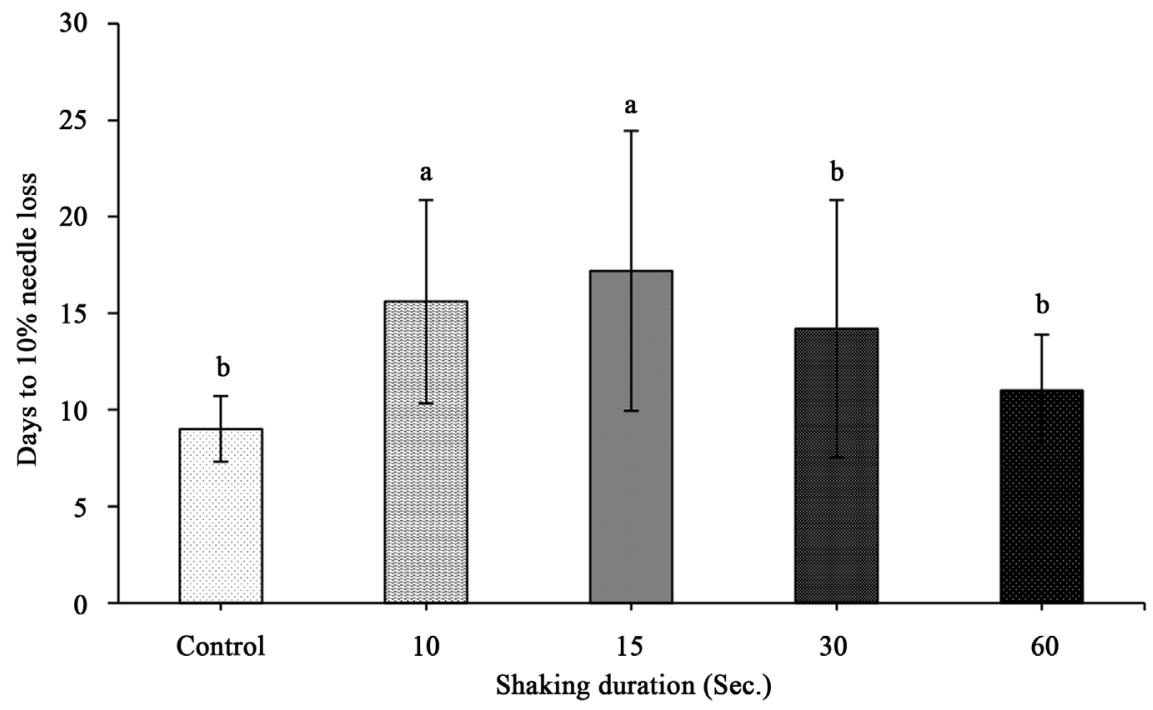

Figure 4. Days to $10 \%$ needle loss of shaken balsam fir trees for a duration with standard error bars $(n=5)$. Any two means followed by same letters are not significantly different $(\mathrm{p} \leq 0.05)$.

3) Average water use (AWU)-Water consumption increased by $11 \%(0.11$ $\left.\mathrm{mL} \cdot \mathrm{g}^{-1} \cdot \mathrm{day}^{-1}\right)$ in baled trees compared to control $\left(0.09 \mathrm{~mL} \cdot \mathrm{g}^{-1} \cdot \mathrm{day}^{-1}\right)$. On the other hand, there was no significant difference in water consumption when shaken trees were compared to control. However, there was an increase in water consumption by $2.5 \%\left(0.11 \mathrm{~mL} \cdot \mathrm{g}^{-1} \cdot \mathrm{day}^{-1}\right)$ when shaken trees were compared to baled trees $\left(0.10 \mathrm{~mL} \cdot \mathrm{g}^{-1} \cdot \mathrm{day}^{-1}\right)$ (Figure 6).

4) Ethylene evolution-Data showed that shaking of trees had a significant effect on ethylene evolution (Table 1 ). We observed that on average, the control trees emitted $32.65 \%$ more $\left(0.65 \mu \mathrm{L} \cdot \mathrm{g}^{-1} \cdot \mathrm{h}^{-1}\right)$ of ethylene compared to the shaken 


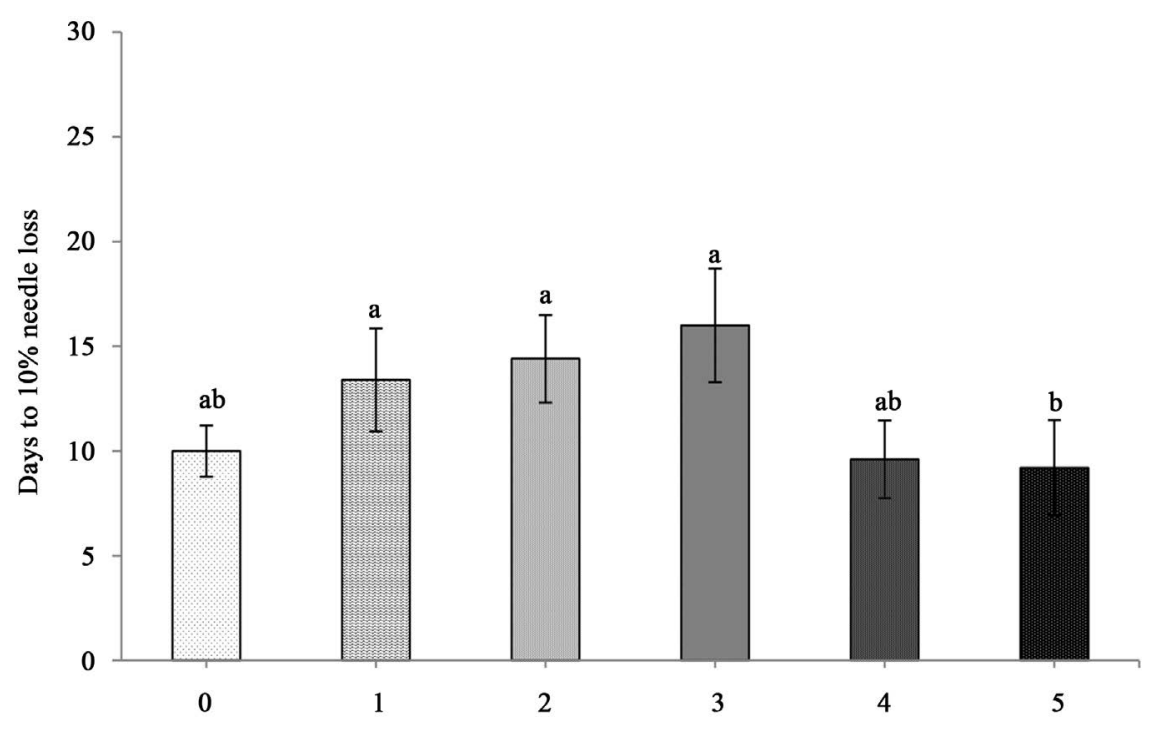

Figure 5. Days to $10 \%$ needle loss of baled balsam fir trees with standard error bars $(n=$ $5)$. Any two means followed by same letters are not significantly different ( $\mathrm{p} \leq 0.05)$.

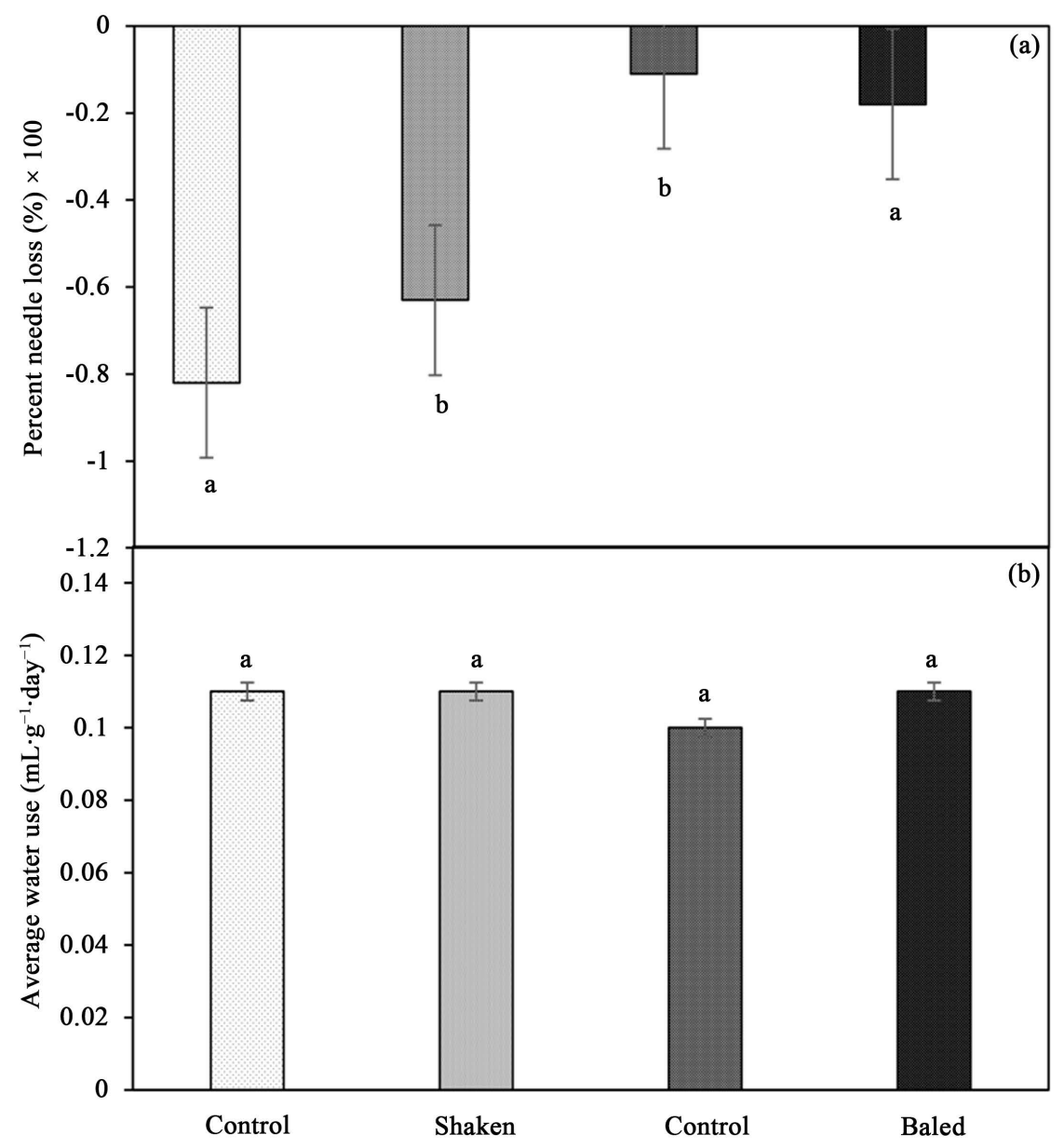

Figure 6. (a) Average water use of shaken and baled balsam fir trees. (b) Percentage needle loss of shaken and baled balsam fir trees with standard error bars $(n=5)$. Any two means followed by same letters are not significantly different $(\mathrm{p} \leq 0.05)$. 
trees $\left(0.49 \mu \mathrm{L} \cdot \mathrm{g}^{-1} \cdot \mathrm{h}^{-1}\right)$. There was no significant difference between the different levels of shaking duration. However, an increase in ethylene emission with increase in shaking duration (Figure 1(b)) was observed. On the other hand, data on baling showed that baling of trees had a significant negative effect on ethylene evolution (Table 1). The data showed that baling of only one tree resulted in two-fold increase in ethylene concentration $\left(0.48 \mu \mathrm{L} \cdot \mathrm{g}^{-1} \cdot \mathrm{h}^{-1}\right)$ compared to the control $\left(0.21 \mu \mathrm{L} \cdot \mathrm{g}^{-1} \cdot \mathrm{h}^{-1}\right)$. There was also a decrease in ethylene evolution with increase in number of trees per bale with five trees per bale recording the lowest ethylene evolution of $0.20 \mu \mathrm{L} \cdot \mathrm{g}^{-1} \cdot \mathrm{h}^{-1}$ (Figure 2(b)).

5) Volatile terpene compound evolution-Baling of trees had a significant effect on VTC evolution (Table 1). It was evident that baled trees emitted 10\% more total VTCs $\left(7.25 \mathrm{mM} \cdot \mathrm{g}^{-1} \cdot \mathrm{h}^{-1}\right)$ compared to the control $\left(6.61 \mathrm{mM} \cdot \mathrm{g}^{-1} \cdot \mathrm{h}^{-1}\right)$ (Figure 7). The maximum VTC concentration was observed in baling of 2 trees $\left(11.24 \mathrm{mM} \cdot \mathrm{g}^{-1} \cdot \mathrm{h}^{-1}\right)$, on the contrary the lowest was observed in baling of 4 trees $\left(5.04 \mathrm{mM} \cdot \mathrm{g}^{-1} \cdot \mathrm{h}^{-1}\right.$ ) (Figure 7).

6) Relationship between ethylene, VTC and postharvest needle characteristics

There was a significant positive relationship between ethylene evolution and NRD. A significant correlation was observed between NRD and ethylene evolution in baled balsam fir trees with $\mathrm{R}^{2}$ value of 0.052 and $p$ value of 0.048 (Table 2). Ethylene evolution showed to increase to a peak evolution of $3.36 \mu \mathrm{L} \cdot \mathrm{g}^{-1} \cdot \mathrm{h}^{-1}$ four weeks postharvest, nonetheless decreased after that until complete needle loss was reached (Figure 8). On the other hand, a significant correlation was detected between NRD and VTC evolution with $\mathrm{R}^{2}$ value of 0.159 and $P$ value of 0.019 (Table 2). Similar to ethylene, a peak in VTC evolution was observed on the fourth week to a rate of $13.45 \mathrm{mM} \cdot \mathrm{g}^{-1} \cdot \mathrm{h}^{-1}$ (Figure 8 ).

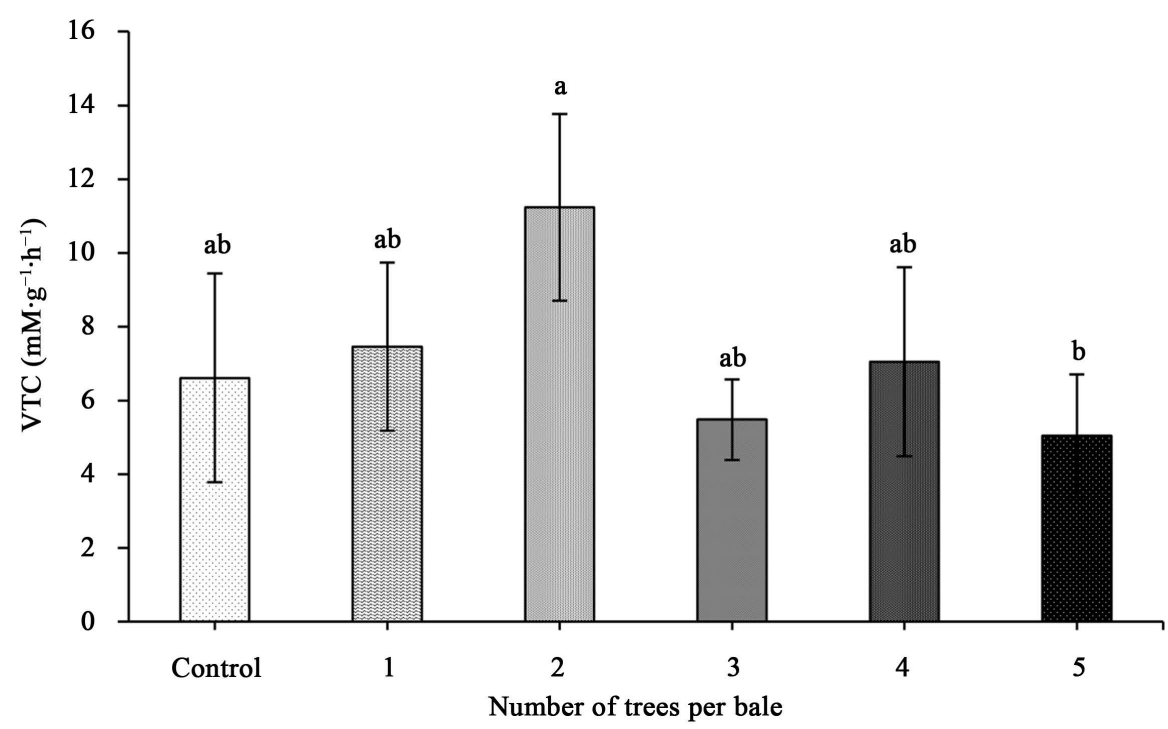

Figure 7. Volatile terpene compounds evolution of baled balsam fir trees with standard error bars $(n=5)$. Any two means followed by same letters are not significantly different $(\mathrm{p} \leq 0.05)$. 
Table 2. The $\mathrm{R}^{2}$ and statistical $\mathrm{p}$ values for the relationship between ethylene and total volatile terpene compound evolution and NRD of baled balsam fir trees.

\begin{tabular}{ccc}
\hline & \multicolumn{2}{c}{ NRD of trees } \\
\cline { 2 - 3 } & $\mathrm{R}^{2}$ & $\mathrm{p}$ \\
\hline Ethylene & 0.052 & $\mathbf{0 . 0 4 8 ^ { * }}$ \\
VTC & 0.159 & $\mathbf{0 . 0 1 9 ^ { * }}$ \\
\hline
\end{tabular}

${ }^{* *}$ denotes a significant effect where $\mathrm{p} \leq 0.05$.

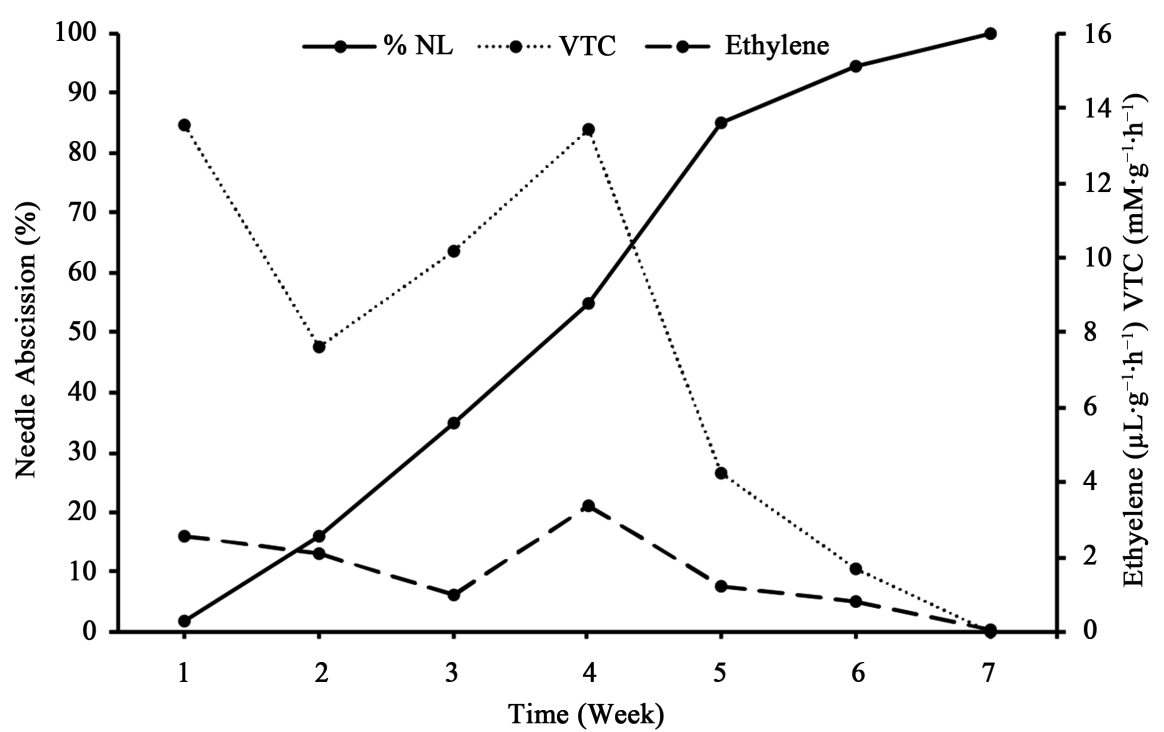

Figure 8. Dynamics of postharvest ethylene and VTC evolution in relation to needle abscission of balsam fir (Abies balsamea L.) trees.

\section{Discussion}

It has been studied that the ability of a tree to withstand any postharvest stress depends largely on the ability to rehydrate [16] [17], therefore, it has been suggested that any mechanical activity such as shaking or baling could lead to cavitation of water columns in the xylem or disrupt the pathway of water transport, which will negatively influence the postharvest quality of the tree [18] [19]. One would expect that increasing the duration for shaking trees and number of trees in a bale will result in a significant decrease in water use compared to their respective controls, resulting in significant needle loss. Data from our study did not support this theory. There were no significant differences in AWU among treated and untreated trees observed, therefore we cannot speculate water stress in treated trees. A possibility could be that water stress and early postharvest needle loss was not observed in our study because the level of shaking and baling imposed on trees were not intense enough to cause significant mechanical damage, and consequent loss of turgor of the epidermal cells of needles as reported by Grace et al. [18].

Data showed significant decrease in PNL of both shaken and baled trees by $16 \%$ and $13 \%$, respectively in comparison to control. A decrease in PNL with the 
increase in shaking duration and number of trees in a bale was observed. This can be explained by physiological perturbation where plants respond to mechanical-induced stress (MIS) by going through several physiological changes [4]. One way plants respond to MIS is through stomatal regulation, we can therefore speculate that in response to both shaking and baling these trees maintained open stomata to allow both water and $\mathrm{CO}_{2}$ uptake. This is beneficial to trees' survival, which is evident in reducing postharvest needle loss and also increasing NRD. Similar results have been reported by Grace et al. [18] and Grace [20] where MIS in F. arundinacea through exposure to wind had more widely opened stomata than control. Other studies in the past have supported this phenomenon, where plants like Prunella vulgaris have been reported to recover from stress by rubbing of stem [5]. Suge [21] also concluded that stroked leaves of Phaseolus vulgaris loss less water and reduced leaf abscission compared to untreated plants.

Historically, ethylene evolution has been reported to significantly increase with drought in jack and white pines [17] [22], with biotic stresses in silver fir [23], and ozone stress in Norway spruce [24]. Though it is involved in a host of physiological processes, ethylene evolution due to stress is often associated with senescence and abscission as a stress response [13] [17] [25]. Although there was no indication of water stress in this study, we recorded significant increase in ethylene evolution $\left(0.05-3.36 \mu \mathrm{L} \cdot \mathrm{g}^{-1} \cdot \mathrm{h}^{-1}\right)$ from the beginning to the end the study and in baled trees compared to the control. One would then ask if there could be an alternative signal (s) other than water stress that can trigger ethylene evolution. Some studies have suggested that ethylene independently or together with JA serve as signal molecules to regulate the pin gene expression in response to wounding of plants [26] [27] [28]. Ethylene release has also been found to increase in many different plant species following mechanical perturbation [29] [30]. This could explain the detection of ethylene in our study as a result of plant wounding through shaking and baling. A slow ethylene evolution was observed in the first few weeks, but reached a peak several weeks after harvest. This pattern of ethylene evolution is also similar to studies by Alvarez-Montezuma et al. [31] and McDonald et al. [13].

Prior to peak needle loss a peak in VTC evolution, irrespective of the treatment was observed. We also observed a higher VTC evolution in treated trees than the control. VTCs have been described as protective secondary molecules biosynthesized to protect the photosynthetic apparatus against oxidative damage [32] [33]. Mechanical stress, wounding and environmental stress such as drought have been shown to trigger the active production of reactive oxygen intermediates (ROIs) by NADPH oxidases [34] [35]. This has been known to pose a threat to cells and act as a signal for the activation of stress response and defense pathways [36]. Since oxidative stress is known to be linked to cell degradation and abscission [37], VTCs have been speculated to be synthesized and or evolved by plants during cell degradation in an effort to slow down or stop ab- 
scission. This could explain the increase in VTC evolution prior to peak needle abscission. The trend of VTC evolution in this study is similar to trends reported by Korankye et al. [14].

\section{Conclusion}

In summary, shaking and baling of balsam fir trees affect the postharvest needle retention characteristics. PNL was significantly lower when trees were generally shaken, however, there is physiological benefit of lower PNL and higher NRD when trees are shaken for $30 \mathrm{sec}$. PNL was significantly low in non-baled trees compared to the baled trees. It is therefore undoubtedly better not to bale the trees at all, however, if baling is imperative it is therefore recommended to bale at least 5 trees since our study showed that trees from the bale of 5 retained the highest amount of needles for longer period. Ethylene and VTC evolution were consistent with the trends in PNL. We observed a decreasing evolution of ethylene and VTC when percentage needle loss decreased with increase in either baling period or number of trees per bale. We also observed a peak in both ethylene and VTC evolution in week four, a weak prior to peak needle loss. These findings on ethylene and VTC and their impact on postharvest abscission significantly enhance our understanding of the intricate relationship between postharvest handling processes of shaking, and baling and endogenous hormonal and secondary metabolite changes in balsam fir trees.

\section{References}

[1] CTCNS (2016) Christmas Tree Council of Nova Scotia. http://www.ctcns.com/

[2] Parkhurst, D.F., Pearman, G.I., Neel, P.L. and Harris, R.W. (1972) Tree Seedling Growth: Effect of Shaking. Science, 175, 918-919.

[3] Biddington, N.L. (1986) The Effects of Mechanically-Induced Stress in Plants: A Review. Plant Growth Regulation, 4, 103-123. https://doi.org/10.1007/BF00025193

[4] Chehab, E.W., Eich, E. and Braam, J. (2009) Thigmomorphogenesis: A Complex Plant Response to Mechano-Stimulation. Journal of Experimental Botany, 60, 43-56. https://doi.org/10.1093/jxb/ern315

[5] Jaffe, M.J. and Forbes, S. (1993) Thigmomorphogenesis: The Effect of Mechanical Perturbation on Plants. Plant Growth Regulation, 12, 313-324. https://doi.org/10.1007/BF00027213

[6] Biro, R.L., Hunt, E.R. and Jaffe, M.J. (1980) Thigmomorphogenesis: Changes in Cell Division and Elongation in the Internodes of Mechanically-Perturbed or Ethrel-Treated Bean Plants. Annals of Botany, 45, 655-664. https://doi.org/10.1093/oxfordjournals.aob.a085874

[7] Chehab, E.W., Kaspi, R., Savchenko, T., Rowe, H., Negre-Zakharov, F., Kliebenstein, D. and Dehesh, K. (2008) Distinct Roles of Jasmonates and Aldehydes in Plant-Defence Responses. PLOS ONE, 3, e1904. https://doi.org/10.1371/journal.pone.0001904

[8] Chen, H., Wilkerson, C.G., Kuchar, J.A., Phinney, B.S. and Howe, G.A. (2005) Jasmonate-Inducible Plant Enzymes Degrade Essential Amino Acids in the Herbivore Midgut. Proceedings of the National Academy of Sciences of the United States of America, 102, 19237-19242. https://doi.org/10.1073/pnas.0509026102 
[9] Karban, R. and Baldwin, I.T. (1997) Induced Responses to Herbivory. University of Chicago Press, Chicago. https://doi.org/10.7208/chicago/9780226424972.001.0001

[10] Green, T.R. and Ryan, C.A. (1972) Wound-Induced Proteinase Inhibitor in Plant Leaves: A Possible Defence Mechanism against Insects. Science, 175, 776-777. https://doi.org/10.1126/science.175.4023.776

[11] Jaffe, M.J. and Biro, R. (1979) Thigmomorphogenesis: The Effect of Mechanical Perturbation on the Growth of Plants, with Special Reference to Anatomical Changes, the Role of Ethylene, and Interaction with Other Environmental Stresses. In: Mussell, H. and Staples, R.C., Eds., Stress Physiology in Crop Plants, John Wiley \& Sons, New York, 25-69.

[12] Salisbury, F.B. (1963) The Flowering Process. Macmillan, New York.

[13] MacDonald, M.T., Rajasekaran, R.L., Martynenko, A.I., Dorais, M., Pepin, S. and Desjardins, Y. (2010) Ethylene Triggers Abscission in Root Detached Balsam Fir. Trees, 24, 879-886. https://doi.org/10.1007/s00468-010-0457-2

[14] Korankye, A.E., Rajasekaran, R.L., Asiedu, S.K. and Forney, C. (2013) Identification and Characterization of Volatile Terpene Compounds (VTCs) in Balsam Fir Seedlings and Mature Trees. Masters Dissertation, Dalhousie University, Halifax.

[15] Dicke, M., Agrawal, A.A. and Bruin, J. (2003) Plants Talk, But Are They Deaf? Trends in Plant Science, 8, 403-405. https://doi.org/10.1016/S1360-1385(03)00183-3

[16] Chastagner, G.A. (1986) Effect of Postharvest Moisture Stress on the Keeping Qualities of Douglas-Fir Chritmas Trees. HortScience, 21, 485-486.

[17] Rajasekaran, L.R. and Blake, T.J. (1999) New Plant Growth Regulators Protect Photosynthesis and Enhance Growth under Jack Pine Seedlings. Journal of Plant Growth Regulation, 18, 175-181. https://doi.org/10.1007/PL00007067

[18] Grace, J., Pitcairn, C.E.R., Russell, G. and Dixon, M. (1982) The Effect of Shaking on Growth and Water Relations of Festuca arundinacea Schreb. Annals of Botany, 49, 207-215. https://doi.org/10.1093/oxfordjournals.aob.a086241

[19] Rajasekaran, R.L. and MacDonald, M.T. (2015) Understanding the Physiology of Postharvest Needle Abscission in Balsam Fir. Frontiers in Plant Science, 6, 1069.

[20] Grace, J. (1974) The Effect of Wind on Grasses 1. Cuticular and Stomatal Transpiration. Journal of Experimental Botany, 25, 542-551.

https://doi.org/10.1093/jxb/25.3.542

[21] Suge, H. (1980) Dehydration and Drought Resistance in Phaseolus vulgaris as Affected by Mechanical Stress. Reports of the Institute for Agricultural Research, Tohoku University, Vol. 31, 1-10.

[22] Islam, M.A., MacDonald, S.E. and Zwiazek, J.J. (2003) Responses of Black Spruce (Picea mariana) and Tamarack (Larix laricina) to Flooding and Ethylene. Tree Physiology, 23, 545-552. https://doi.org/10.1093/treephys/23.8.545

[23] Fuhrer, J. (1985) Ethylene Production and Premature Senescence of Needles from Fir Trees (Abies alba). European Journal of Plant Pathology, 15, 227-236. https://doi.org/10.1111/j.1439-0329.1985.tb00890.x

[24] Van denDriessche, R. and Langebartels, C. (1994) Foliar Symptoms, Ethylene Biosynthesis, and Water Use of Young Norway Spruce (Picea abies (L.) Karst.) Exposed to Drought and Ozone. Water Air Soil Pollution, 78, 153-168. https://doi.org/10.1007/BF00475674

[25] Brown, K.M. (1997) Ethylene and Abscission. Physiologia Plantarum, 100, 567-576. https://doi.org/10.1111/j.1399-3054.1997.tb03062.x 
[26] Kende, H. (1993) Ethylene Biosynthesis. Annual Review of Plant Physiology, 44, 283-307. https://doi.org/10.1146/annurev.pp.44.060193.001435

[27] Lincoln, J.E., Campbell, A.D., Oetiker, J., Rottmann, W.H., Oeller, P.W., Shen, N.F. and Theologis, A. (1993) LE-ACS4, a Fruit Ripening and Wound-Induced 1-Aminocyclopropane-1-carboxylate Synthase Gene of Tomato (Lycopersicon esculentum). Expression in Escherichia coli, Structural Characterization, Expression Characteristics, and Phylogenetic Analysis. The Journal of Biological Chemistry, 268, 19422-19430.

[28] O’Donnell, P.J., Calvert, C., Atzorn, R., Wasternack, C., Leyser, H.M.O. and Bowles, D.J. (1996) Ethylene as a Signal Mediating the Wound Response of Tomato Plants. Science, 274, 1914-1917. https://doi.org/10.1126/science.274.5294.1914

[29] Biro, R.L. and Jaffe, M.J. (1984) Thigmomorphogenesis: Ethylene Evolution and Its Role in the Changes Observed in Mechanically Perturbed Bean Plants. Acta Physiologiae Plantarum, 62, 289-296. https://doi.org/10.1111/j.1399-3054.1984.tb04575.x

[30] Telewski, F.W. (1995) Wind Induced Physiological and Developmental Responses in Trees. In: Coutts, M.P. and Grace, J., Eds., Wind and Trees, Cambridge University Press, Cambridge, 237-263. https://doi.org/10.1017/CBO9780511600425.015

[31] Alvarez-Moctezuma, J.D., Alia-Tejacal, I., Colinas-Leon, M.T. and Castellanos, S.J. (2007) Interspecific Differences in Postharvest Quality on Mexican Christmas Trees. Silvae Genetica, 56, 65-73. https://doi.org/10.1515/sg-2007-0010

[32] Loreto, F. and Velikova, V. (2001) Isoprene Produced by Leaves Protects the Photosynthetic Apparatus against Ozone Damage, Quenches Ozone Products, and Reduces Lipid Peroxidation of Cellular Membranes. Plant Physiology, 127, 1781-1787. https://doi.org/10.1104/pp.010497

[33] Loreto, F., Pinelli, P., Brancaleoni, E. and Ciccioli, P. (2004) 13C Labelling Reveals Chloroplastic and Extra-Chloroplastic Pools of Dimethylallyl Piroposphate and Their Contribution to Isoprene Formation. Plant Physiology, 135, 1903-1907. https://doi.org/10.1104/pp.104.039537

[34] Hammond-Kosack, K.E. and Jones, J.D.G. (1996) Resistance Gene-Dependent Plant Defense Responses. Plant Cell, 8, 1773-1791. https://doi.org/10.1105/tpc.8.10.1773

[35] Orozco-Cardenas, M. and Ryan, C.A. (1999) Hydrogen Peroxide Is Generated Systemically in Plant Leaves by Wounding and System in via the Octadecanoid Pathway. Proceedings of the National Academy of Sciences, 96, 6553-6557. https://doi.org/10.1073/pnas.96.11.6553

[36] Knight, H. and Knight, M.R. (2001) Abiotic Stress Signaling Pathways: Specificity and Cross-Talk. Trends in Plant Science, 6, 262-267. https://doi.org/10.1016/S1360-1385(01)01946-X

[37] Valko, M., Morris, H. and Cronin, M.T.D. (2005) Metals, Toxicity and Oxidative Stress. Current Medicinal Chemistry, 12, 1161-1208. https://doi.org/10.2174/0929867053764635 